\title{
A Fluency-based Programme with a Clutterer: a Case Study
}

\author{
Benita Cohn BA (Sp \& H Th) (Witwatersrand) \\ Joan Girson BA(Log) (Witwatersrand) \\ Margaret Marks Wahlhaus MA (Log)(Witwatersrand) \\ Department of Speech Pathology and Audiology, \\ University of the Witwatersrand, Johannesburg
}

\begin{abstract}
$A B S T R A C T$
A fluency-based programme developed for stutterers was used with a clutterer, and its effects were assessed. Pre-and post-intervention measures included dysfluencies, articulation errors, paralinguistic features, intelligibility, rate and attitude. Results indicated an overall improvement in most of the speech parameters, with particularly interesting changes in attitude. The implications of these results are discussed.

OPSOMMING

'n Vlotheidsprogram ontwerp vir hakkelaars is met 'n stamelaar uitgevoer, en die uitwerking daarvan is bepaal. Metings voor en na afloop $v a n$ die behandeling het die volgende ingesluit: vlotheidsafwykings, artikulasiefoute, paralinguistiese eienskappe, verstaanbaarheid, tempo en houding. Die resultate het op 'n algemene verbetering t.o.v. die meeste spraakparameters gedui met veral interessante veranderings t.o.v. houding. Die implikasies van hierdie resultate word bespreek.
\end{abstract}

For many years research on pathological states of non-fluency has focused almost exclusively on the disorder of stuttering. Recently, increased attention has been paid to cluttering which is a contentious issue. It is variously considered a disorder of fluency, of language, and/or of conceptualisation (Luchsinger and Arnold, 1965). Non-communicative concomitants, such as learning and motoric problems have been associated with it (Weiss 1967). The etiology is equally confusing. Some have attributed it to a central language imbalance (Weiss 1964), others to a type of psychoneurological dysfunction' (Uys 1974). Additional confusion is caused by the fact that the term itself is applied by some to describe the symptomatology (Dalton and Hardcastle 1977), and by others to imply an etiological entity (Weiss 1960).

Cluttering is characterized by some symptoms which are considered to constitute the core behaviours of the condition. These are described by Weiss $(1960,1964,1967)$ as obligatory symptoms, assumed to be present in all clutterers, as opposed to the facultative symptoms which are sometimes present. The obligatory symptoms include short attention span and poor concentration, lack of 'complete' awareness of the disorder, and an excessive number of repetitions in speech. The facultative behaviours are slurring, elisions, iterations and transpositions of phonemes, syllables and words. Additional facultative problems are alexia, agraphia, amusia and voice problems (Weiss 1964, Grewel 1970, De Fusco and Menken 1979) as well as those associated with minimal brain dysfunction (Langová and Morávek 1970). According to Freund (cited in Weiss 1960), stuttering may frequently be confused with the disorder, as both present with symptoms of dysfluency. Dysfluency in cluttering is manifested on various levels (Dalton and Hardcastle 1977). At the phonetic level there may be repetitions of initial sounds, syllables or words, or prolongations of sound segments. At the grammatical level, co-ordinating conjunctions for example may be omitted. At the prosodic level there may be a succession of similar stereotyped intonation patterns, and at the lexical/semantic level, abnormal development of logical sequences of ideas in a discourse may occur. With regard to pausing, dysfluency may be manifested by drawlings and interjections (Grewel 1970, Weiss 1964, 1967, De Fusco and Menken 1979, Becker and Grundman 1970, Bradford 1970).

(c) SASHA 1985
Cluttering was for a long time considered virtually untreatable. The first documented treatment for clutterers was by Froeschels in 1931 (as cited by Wolk 1980). The focus of cluttering treatment has been to compensate for specific areas of difficulty, such as tachylalia, insufficiency of articulation, vocabulary and language formulation (Weiss 1960), lack of verbal attention (Langová and Morávek 1970) as well as monotony of the voice of the clutterer (Weiss 1960). Weiss (1960) is of the opinion that prognosis is poor for many clutterers. However, Dalton and Hardcastle (1977) view the key factor to prognosis as lying in the determination and hard work of the particular clutterer.

The fact that the element of dysfluency is so basic to cluttering, directed the present researchers' consideration of the application to cluttering of a technique designed for the remediation of stutterers' dysfluencies. A number of speech-fluency procedures applied to the problem of stuttering have been reported during the past decade. Having considered a number of these fluency-based techniques, it was decided to utilise the stutter-free speech procedure as outlined by Shames and Florance in 1980 . Besides: being directed to the attainment of fluency, this technique seems particularly appropriate for clutterers as it incorporates so many;other aspects of their problem. Weiss (1967) has stated that heightened attention to the speech act improves the clutterers speech problem. Shames and Florance (1980) emphasize the development of selfmonitoring skills in their clients, thus demanding attention to their speech act. Excessive speed of delivery is often a feature of cluttered speech and modification to a slower rate seems necessary. Both speech and reading rates are modified using this fluency based technique (Shames and Florance 1980). The articulation of the clutterer is often slurred, unintelligible and "drunken" sounding. The Shames and Florance (1980) technique aims to teach the speaker a way of articulating sounds using little pressure. It was postulated that this technique might improve the clutterer's articulation. Andrews and Ingham (1972) have proposed evaluation standards with regard to the improvement of fluency. These standards have been met by the Shames and Florance (1980) technique in that there is continued measurement of fluency, speaking rate and normal prosody, transfer of fluency to extraclinical settings, and measurement of the permanence of fluency. 
For these reasons, and in view of the paucity of the literature on the treatment of cluttering, the major aim of the present study was designed to assess the therapeutic effectiveness of a fluency-based programme, namely the Shames and Florance (1980) 'stutter-free' speech technique, on the speech of an adult clutterer.

\section{METHOD}

SUBJECT

The subject was a 20 year old male Technicon student who was diagnosed as a clutterer by three graduate speech pathologists. This diagnosis was made according to a checklist devised by one of the

Table 1 A checklist of the diagnostic criteria for the classification of the subject as a 'clutterer'

\begin{tabular}{|c|c|c|c|c|c|c|c|c|c|c|c|}
\hline \multirow{6}{*}{ o } & A & SHORT ATTENTION SPAN AND POOR CONCENTRATION & \multirow{4}{*}{1} & & & & & & \multirow{2}{*}{\multicolumn{2}{|c|}{3}} \\
\hline & 1 & General disordcrliness & & 2 & & & & & & & \\
\hline & 2 & General restlessness & & & & & & & 1 & 2 & 3 \\
\hline & 3 & Hyperactivity (quick movements) & & & & 1 & 2 & 3 & & & \\
\hline & 4 & Impatient listener & & 2 & 3 & 1 & & & & & \\
\hline & B & LACK OF AWARENESS OF DISORDER & & & & & & & 1 & 2 & 3 \\
\hline & c & EXCESSIVE NUMBER OF REPETITIONS & & & & 1 & 2 & 3 & & & \\
\hline & $\mathbf{D}$ & PROLONGATIONS/DRAWLINGS AND INTERJECTIONS & & & & & & & & & \\
\hline & 1 & Drawlings & & & & 1 & 2 & 3 & & & \\
\hline & 2 & Interjections & & & & 1 & 2 & 3 & & & \\
\hline & 3 & Addition of phonemes & & & & 1 & 2 & 3 & & & \\
\hline & 4 & Addition of sy!lables & & & & 1 & 2 & 3 & & & \\
\hline & 5 & Addition of words & & & & $\mathrm{I}$ & 2 & 3 & & & \\
\hline & E & TACHYLALIA & & & & & & & & & \\
\hline & 1 & Excessive speed in speech & & & & 1 & 2 & 3 & & - & \\
\hline & 2 & Excessive speed in reading & & & & & & & 1 & 2 & 3 \\
\hline & 3 & Festinating & & & & & & & 1 & 2 & 3 \\
\hline & $\mathbf{F}$ & POOR ARTICULATION & & & & & & & & & \\
\hline & 1 & Lack of precision & & & & 1 & 2 & 3 & & & \\
\hline & 2 & Slurring & & & & 1 & 2 & 3 & & & \\
\hline & 3 & Non-systematic articulatory breakdowns & & & & $\mathrm{I}$ & 2 & 3 & & & \\
\hline & 4 & Variable occurrence of imprecise consonants & & & & 1 & 2 & 3 & & & 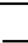 \\
\hline & 5 & Ettipsis, i.e. omission of sounds, syllables and words & & & & 1 & & & & 2 & 3 \\
\hline & 6 & Spoonerisms, i.e. cranspositions of sounds, syllables and words & 1 & 2 & 3 & & & & & & \\
\hline$r$ & 7 & Heterolopy, i.e. displacement of sounds & 1 & 2 & 3 & & & & & & \\
\hline$F$ & 8 & Metathesis, i.e. inversion of the order of sounds & & & & & & 3 & $\mathrm{I}$ & 2 & \\
\hline & 9 & Telescoping, i.c. omissios of one clement of a blend & & & & & & & 1 & 2 & 3 \\
\hline & G & INTELLIGIBILITY & & & & & & & & & \\
\hline & 1 & Reading & & & & & & & 1 & 2 & 3 \\
\hline & 2 & Spontaneous speech & & & & & & & 1 & 2 & 3 \\
\hline & $\mathrm{H}$ & INFLECTION & & & & & & & & & \\
\hline & 1 & Monotonous & & & & & & & 1 & 2 & 3 \\
\hline & 2 & Lack of rhythm & & & & & & & 1 & 2 & 3 \\
\hline & 3 & Peculiaritics in repetition of melody & 1 & & 3 & & & & & 2 & \\
\hline & 1 & WOICE & & & & & & & & & \\
\hline & 1 & Lacking in intonation & & & & & & & 1 & 2 & 3 \\
\hline & 2 & Low pitched & 1 & 2 & 3 & & & & & & \\
\hline & 3 & Nasal quality & & & & & & 3 & 1 & 2 & \\
\hline & J & WRITING & & & & & & & & & \\
\hline & 1 & Repetition & 1 & 2 & 3 & & & & & & \\
\hline & 2 & Revisions & 1 & 2 & 3 & & & & & & \\
\hline & 3 & Transpositions & 1 & 2 & 3 & & & & & & \\
\hline & 4 & Omissions & 1 & 2 & 3 & & & & & & \\
\hline & 5 & Corrections & $\mathrm{I}$ & 2 & 3 & & & & & & \\
\hline & 6 & Spelling difficułtics & 1 & 2 & 3 & & & & & & \\
\hline & 7 & Irregular sprawling & $\mathrm{I}$ & 2 & 3 & & & & & & \\
\hline & $\mathbf{K}$ & EXPRESSIVE LANGUAGE & & & & & & & & & \\
\hline & 1 & Disorganized sentence structure & & & & 1 & 2 & 3 & & & \\
\hline & 2 & Groping for words & & & & 1 & & 3 & & 2 & \\
\hline & 3 & Reduccd vocabulary & & & & 1 & 2 & 3 & & & \\
\hline & 4 & lnversions of word order & 1 & & & & 2 & 3 & & & \\
\hline F & $\mathbf{L}$ & VARIABILITY & & & & & & & & & \\
\hline & 1 & Specch improves when speaking to a stranger & 1 & 2 & 3 & & & & & & \\
\hline & 2 & Speech improves when speaking slowly & & & & 1 & 2 & 3 & & & \\
\hline
\end{tabular}

2 Speech improves when speaking slowly 
experimenters, based on the symptoms which have been associatwiagnostic checklist containing the judges' ratings is presented in Table 1 .

On the basis of the large proportion of symptoms being noted as present, the authors decided that the subject could be considered as a clutterer. The subject's hearing, intelligence and neurological integrity were within normal limits. There was no history of previous therapy. The subject's laterality was mixed. This shift of handedness is commonly described in clutterers (Arnold 1970). A family history of cluttering on the subject's paternal side was reported. This accords with findings of an hereditary factor in the family of the clutterer (Weiss 1967, Dalton and Hardcastle 1977, Uys 1974).

\section{PROCEDURE}

\section{INTERVENTION}

Intensive intervention therapy was carried out by the experimenter over a three-week period. The programme employed was the 'Stutter-Free Speech Technique' of Shames and Florance (1980). There were 15 intervention sessions, of one hour each. Therapy involved the carrying out of the first four stages of the Shames and Florance programme i.e. volitional control, self reinforcement, transfer and training in unmonitored speech. Intervention commenced at a prolonged speech rate of 30 words per minute and increased to a rate of 85 words per minute.

To evaluate the effectiveness of this technique on the subject's speech, pre- and post-intervention measurements were taken and evaluated by a number of raters. Rating measures will be discussed in detail below.

\section{COLLECTION OF DATA}

Pre- and post-intervention recordings were made in a sound proof recording room at the Speech and Hearing Clinic, University of the Witwatersrand. Videofilming was done through a one-way mirror using a National VHS video camera. For both sets of recordings a spontaneous speech sample was obtained where the subject was required to talk about his job, his hobbies and his favourite country. To lessen the possible effects of adaptation, he was required to talk about a different country and different hobbies during the second recording. To obtain a reading sample, he was required to read "The Rainbow Passage" and "Arthur the Young Rat"' (Johnson, Darley and Spriestersbach 1963).

The pre-assessment recordings were made one day prior to the commencement of therapy and the post-assessment recordings, one day after termination of the intensive period of three weeks. For postassessment measures, the subject was not instructed to talk using monitored or unmonitored speech, as it was felt this most closely resembled a normal speaking situation.

It is obvious that more definite conclusions concerning the effectiveness of the programme could have been drawn if several further assessments had been carried out at various time periods after the termination of the programme. This is particularly relevant in terms of the carry-over problems shown in stuttering therapy.

Data were analysed by two different groups of raters. Both groups were unaware whether the material they were rating was recorded pre- or post-therapeutically in order to reduce any rater expectation and bias (Rosenthal and Rosnow as cited in Silverman 1977).

\section{A. Ratings by three speech pathologists}

In order to assess the presence or absence of specific cluttering symptoms in the subject's speech, both pre- and post- intervention, the experimenter devised a speech profile. This profile consisted of selected items in the original diagnostic checklist. More specifically, these were those items concerned with dysfluency, poor articulation and paralinguistic features. This profile was rated by three graduate speech pathologists who had had no previous contact with the subject nor knowledge of the aims of the study. In accordance with Rosenthal's view, that an observer's outcome expectations can bias the measurements he makes (Silverman 1977), symptoms were scored in terms of general frequency analysis - always, most of the time, sometimes, seldom and never.

\section{B. Ratings by three lay listeners}

To reflect the approach of the average listener who has minimal insight into the symptoms of cluttering, three lay listeners were asked to rate the data in terms of intelligibility, defined by Le Mesurier and McIntosh (1966), as speech that can be understood and is comprehensible to the listener. They were also asked to mark rate of speech, presence of stuttering, and monotony. Symptoms were scored in terms of general frequency analysis - always, most of the time, sometimes, seldom and never.

\section{Objective rate of speech}

This was determined by counting the number of words used per minute in conversation and reading, both pre- and post-intervention. This was carried out by the experimenter and confirmed by an independent rater.

\section{Attitude to speech}

The subject's attitude to his speech was assessed on the "S-scale of Communication Attitudes" (Erickson 1969), which was administered by the experimenter both pre- and post-intervention. Despite the fact that this scale was specifically designed for stutterers, it was felt by the authors that the areas covered could be considered applicable to clutterers as well.

\section{RESULTS AND DISCUSSION}

\section{A. SPEECH PROFILE AS RATED BY SPEECH PATHOLOGISTS 1. DYSFLUENCIES}

As is evident in Table 2, there is a difference in the number of dysfluencies observed in the pre- and post-intervention situation. All three raters noted a decrease in repetitions, prólongations/drawlings and interjections, with ratings moving from always present (I) to seldom present (IV) (see Table 2). The marked decrease in the frequency of the dysfluent characteristics supports accumulated information that the use of fluency procedures may prove to be of therapeutic value with dysfluent speech (Ingham and Andrews 1971). Results are also in accordance with Ryan and Van Kirk's (1973) description of fluency-based therapy with stutterers. The decrease provides evidence that the initial fluency was reinforced and modified until there was approximation of normal conversational speech in the clinical setting.

\section{POOR ARTICULATION}

Table 3 shows that there has been a notable reduction of poor articulation from the pre- to the post-intervention situations. This lessening of poor articulation post-therapeutically fulfills the demands, made by Weiss (1960) and Langová and Morávek (1970), that an 
A Fluency-based Programme with a Clutterer - a Case Study

aim of cluttering treatment should be to attend to the insufficiency of articulation. Intelligible speech can thus be enhanced.

Table 2 Analysis of Changes of Rating of Dysfluencies in the Pre- to Post-Intervention Recording

\begin{tabular}{|c|c|c|c|c|c|c|}
\hline \multicolumn{2}{|r|}{ PRE-INTERVENTION } & I & u & III & IV & $\mathrm{v}$ \\
\hline A & \multicolumn{6}{|l|}{ PRE-INTERVENTION } \\
\hline 1 & An excessive number in speach & 123 & & & & \\
\hline 2 & An excessive number in reading & 123 & & & & \\
\hline B & \multicolumn{6}{|l|}{ PROLONGATIONS/DRAWLINGS AND INTERJECTIONS } \\
\hline 1 & Drawlings & 123 & & & & \\
\hline 2 & Inverjections & 123 & & & & \\
\hline 3 & Addition of phonemes & 13 & 2 & & & \\
\hline 4 & Addition of syllables & 123 & & & & \\
\hline \multirow[t]{3}{*}{5} & Addition of words & 123 & & & & \\
\hline & \multirow{3}{*}{\multicolumn{6}{|c|}{ An excessive number in speech }} \\
\hline & & & & III & IV & $\mathrm{v}$ \\
\hline A & \multicolumn{6}{|l|}{ POST-INTERVENTLON } \\
\hline 1 & & & & & 123 & \\
\hline \multirow[b]{2}{*}{$\mathbf{B}$} & An excessive number in reading & & & & 123 & \\
\hline & \multicolumn{6}{|l|}{ PROLONGATIONSIDRAWLINGS AND INTERJECTIONS } \\
\hline 1 & Drawilings & & & 3 & 12 & \\
\hline 2 & Interjections & & & & 123 & \\
\hline 3 & Addition of phonemes & & & & 123 & \\
\hline 4 & Addition of syllables & & & & 123 & \\
\hline 5 & Addition of words & & & & 123 & \\
\hline $\begin{array}{l}\text { Rater } \\
\text { Rater } \\
\text { Rater }\end{array}$ & $\begin{aligned} \text { I } & \text { Always } \\
\text { II } & \text { Most of the lime } \\
\text { III } & \text { Sornetimes } \\
\text { IV } & \text { Seldam } \\
\text { V } & \text { Never }\end{aligned}$ & & & & & \\
\hline
\end{tabular}

Table 3 Analysis of Changes of Rating of Poor Articulation in the Pre- to Post-Intervention Recording

\begin{tabular}{|c|c|c|c|c|c|c|}
\hline \multicolumn{2}{|r|}{ PRE-LNTERVENTION } & I & II & UII & IV & $\vec{v}$ \\
\hline c & \multicolumn{6}{|l|}{ POOR ARTICULATION } \\
\hline 1 & Lack of precision & & 123 & & & \\
\hline 2 & Slurring $\quad !$ & & 123 & & & \\
\hline 3 & Non-systematic atticulatory breakdowns & & 123 & & & \\
\hline 4 & Variable occurrence of imprecise consonants & 12 & 3 & & & \\
\hline 5 & Spoonerisms - ite. Iranspositions of sounds, syllabjes and words & & & & 1.23 & \\
\hline 6 & Ellipsis - i.e. omission of sounds, syllables and words & 123 & & & & \\
\hline 7 & Heterotopy - i.e. displacement of sounds & & & & & 123 \\
\hline 8 & Metathesis - i.e. inversion of the order of sounds & & & 2 & 3 & 1 \\
\hline 9 & Telescoping - i.e. omission of one element of a blend & & 123 & & & \\
\hline \multirow{2}{*}{\multicolumn{2}{|c|}{ POST-INTERVENTION }} & & & & & \\
\hline & & 1 & II & III & IV & $\mathrm{v}$ \\
\hline $\mathrm{c}$ & \multicolumn{6}{|l|}{$\begin{array}{l}\text { POST-INTERVENTION } \\
\text { POOR ARTICULATION }\end{array}$} \\
\hline 1 & Lack of precision & & & & 123 & \\
\hline 2 & Slutring & & & 3 & 2 & 1 \\
\hline 3 & Non-systemaric articularory breakdowns & & & & & 123 \\
\hline 4 & Variable occurrence of imprecise consonants & & & & & 123 \\
\hline 5 & Spoonerisms - i.e. transpositions of sounds, syllables and words & & & & & 123 \\
\hline 6 & Ellipsis - i.e. omission of sounds, syllables and words & & & & & 123 \\
\hline 7 & Heterotopy - i.e. displacement of sounds & & & & 2 & 13 \\
\hline 8 & Metathesis - i.e. inversion of the order of sounds & & & & & 123 \\
\hline 9 & Telescoping - i.e. omission of one element of a blend & & & & & 123 \\
\hline \multicolumn{2}{|c|}{$\begin{array}{l}\text { Rater One }-1 \\
\text { Rater Two }-2 \\
\text { Rater Three }-3\end{array}$} & & & & & \\
\hline
\end{tabular}


Table 4 Analysis of Changes of Rating of Paralinguistic Features in the Pre- to Post-Intervention Recording:

\begin{tabular}{|c|c|c|c|c|c|c|c|}
\hline \multicolumn{2}{|r|}{ PRE-INTERVENTION } & & I & II & III & \multirow[t]{2}{*}{ IV } & \multirow[t]{2}{*}{$v$} \\
\hline A & \multicolumn{2}{|l|}{ INFLECTION } & & & & & \\
\hline 1 & \multicolumn{2}{|l|}{ Monotenous } & & & 123 & & \\
\hline 2 & \multicolumn{2}{|l|}{ Lack of rhythm } & & & & 123 & \\
\hline 3 & \multicolumn{2}{|l|}{ Peculiarilies in repetition of melody } & & & & 3 & 12 \\
\hline B & \multicolumn{3}{|l|}{ VorCE } & & & & \\
\hline I & \multicolumn{2}{|l|}{ Lacking in intonation } & & & 123 & & \\
\hline 2 & \multicolumn{2}{|l|}{ Low pitched } & & & 123 & & \\
\hline 3 & \multicolumn{2}{|l|}{ Nasal quality } & & & & 23 & 1 \\
\hline c & \multicolumn{7}{|l|}{ TACHYLALIA } \\
\hline 1 & \multicolumn{2}{|l|}{ Excessive speed in speech } & & 123 & & & \\
\hline 2 & \multicolumn{2}{|l|}{ Excessive speed in reading } & & 123 & & & \\
\hline 3 & \multicolumn{2}{|l|}{ Festinating } & & & 123 & & \\
\hline & \multicolumn{2}{|l|}{ POST -INTERVENTION } & 1 & II & III & IV & $v$ \\
\hline A & \multicolumn{7}{|l|}{ INFLECTION } \\
\hline 1 & \multicolumn{2}{|l|}{ Monoconous } & & & 123 & & \\
\hline 2 & \multicolumn{2}{|l|}{ Lack of thythm } & & & & 123 & \\
\hline 3 & \multicolumn{2}{|l|}{ Peculiarities in repeition of melody } & & & & & 123 \\
\hline B & \multicolumn{7}{|l|}{ VOICE } \\
\hline 1 & \multicolumn{2}{|l|}{ Lacking in intonation } & & & 123 & & \\
\hline 2 & \multicolumn{2}{|l|}{ Low pitched } & & & 123 & & \\
\hline 3 & \multicolumn{2}{|l|}{ Nasal quality } & & & & 23 & 1 \\
\hline c & \multicolumn{7}{|l|}{ TACHYLALIA } \\
\hline 1 & \multicolumn{2}{|l|}{ Excessive speed in speech } & & & & & 123 \\
\hline 2 & \multicolumn{2}{|l|}{ Excessive speed in reading } & & & & & 123 \\
\hline 3 & Festinating & & & & & & 123 \\
\hline $\begin{array}{l}\text { Rater O } \\
\text { Rater T } \\
\text { Rater T }\end{array}$ & $\begin{array}{l}\text { De }-1 \\
\text { Who } \\
\text { Whree } \\
-2\end{array}$ & $\begin{aligned} \text { I } & \text { Always } \\
\text { II } & \text { Most of the time } \\
\text { III } & \text { Sometimes } \\
\text { IV } & \text { Seldom } \\
\text { V } & \text { Never }\end{aligned}$ & & & & & \\
\hline
\end{tabular}

\section{PARALINGUISTIC FEATURES}

As can be seen in Table 4, the ratings remained the same in inflection and voice post-therapeutically. This was unexpected, as the stutter-free speech technique is designed to focus on improving the prosodic elements of speech. However, Shames and Florance (1980) report that difficulties in prosody have often been observed when using this technique. These findings imply strongly, that to make the programme maximally effective for a clutterer, special attention should be paid to inflection and stress exercises, as clutterers are very poor in this area.
With regard to the tachylalic symptom of the subject, there was a marked reduction of excessive speed in spontaneous speech and reading from pre- to post-intervention. Modification to a slower rate appears necessary for a clutterer to establish a more intelligible pattern of speech.

\section{B. RATINGS BY LAY LISTENERS}

It is interesting to note that there was perfect concurrence in the ratings of all three lay listeners for both the pre-and post-intervention periods over all four parameters. All parameters were rated identically for both speech and reading tasks.

\section{INTELILGIBILITY}

Table 5(i) Analysis of Changes in Laymen's Judgements of Intelligibility of the Speech Sample from the Pre- to the PostTherapeutic Recording

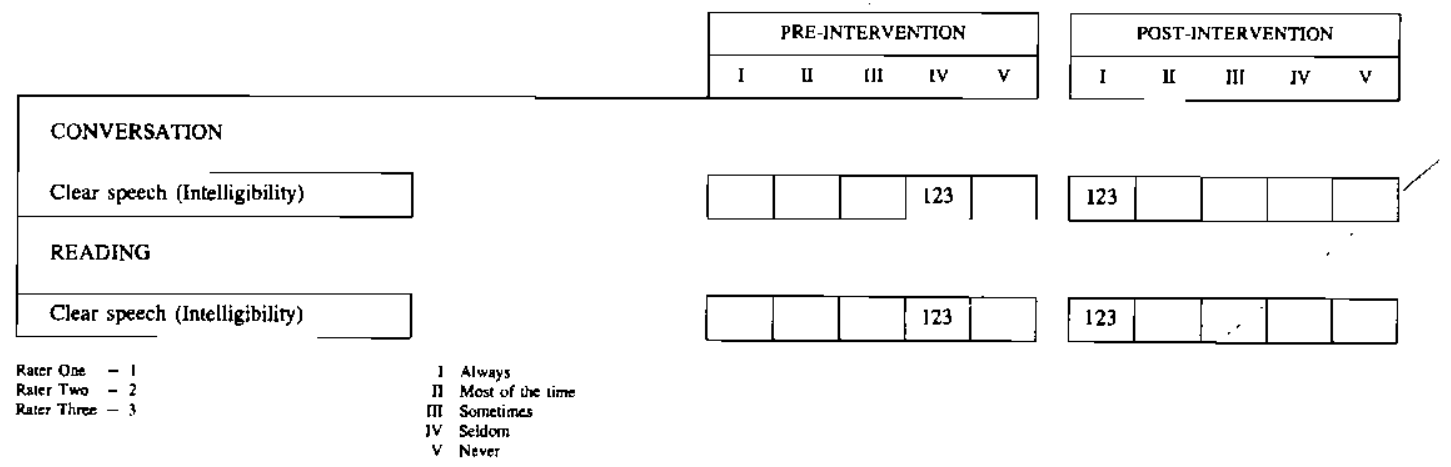


Table 5(ii) Analysis of Changes in Laymen's Judgements of stuttering rate and monotony in the Speech Sample from the Pre- to the Post-Therapeutic Recording

\begin{tabular}{|c|c|c|c|c|c|c|c|c|c|c|c|}
\hline & & \multicolumn{5}{|c|}{ PRE-INTERVENTION } & \multicolumn{5}{|c|}{ POST-INTERVENTION } \\
\hline & & 1 & II & III & IV & $\mathrm{v}$ & I & [] & III & IV & v \\
\hline \multicolumn{12}{|l|}{ CONVERSATION } \\
\hline Fast speech & & & & 123 & & & & & & 123 & \\
\hline Evidence of stuttering & & 123 & & & & & & & & 123 & \\
\hline Monokonous & & & & 123 & & & & 123 & & & \\
\hline \multicolumn{12}{|l|}{ READING } \\
\hline Fast speech & & & & 123 & & & & & & 123 & \\
\hline Evidence of stuttering & & 123 & & & & & & & & 123 & \\
\hline Monotonous & & & & 123 & & & & 123 & & & \\
\hline $\begin{array}{l}\text { ter One }=1 \\
\text { ter Two }-2 \\
\text { tees Three }-3\end{array}$ & $\begin{aligned} \text { I } & \text { Always } \\
\text { II } & \text { Most of the time } \\
\text { III } & \text { Sometimes } \\
\text { IV } & \text { Seldom } \\
\text { V } & \text { Never }\end{aligned}$ & & & & & & & & & & \\
\hline
\end{tabular}

As is evident in Table 5(i) the lay listeners rated the subject's speech as seldom clear (IV) pre-interventionally, and always clear (I) postinterventionally, thus indicating a marked improvement in an important feature of communication.

\section{EVIDENCE OF STUTTERING}

Table 5(ii) shows a marked reduction in dysfluency. The preintervention rating of (I) indicates much evidence of what was described as stuttering, whereas post-intervention ratings noted that stuttering was seldom present. The lay listeners were as aware of the non-fluent speech phenomena as were the graduate speech pathologists. Their perception of improvement substantiates the findings of the trained listener, that this program was effective in reducing non-fluencies.

\section{RATE}

Some slight reduction in rate was noted (see Table 5(ii)) by the listeners from pre- to post-intervention recordings. This parameter can'be considered as corresponding to tachylalia, one of the symptoms usually associated with cluttering. Whereas the lay raters perceived only a slight change in the dimension described to them as 'fast speech', the trained listeners had noted a marked reduction in tachylalia.

\section{MONOTONY}

The lay listeners felt that the monotony of the subject's speech had increased slightly during therapy. This finding was not unexpected as an increase in monotony is often a feature of the technique used, particularly in the early phases. (The final recording was done when the subject was still on Phase 3 of the Shames and Florance programme.) As monotony is one of the symptoms often associated with cluttering, the findings of the lay listeners provide further support that work in the area of building up prosodic elements is specifically needed in a therapy programme for a clutterer.

\section{OBIECTIVE RATE}

There was a significant reduction in the amount of words per minute for both spontaneous speech and reading and it is evident that this method has shown carryover into the spontaneous speech of the subject. The implications for therapy are clear. Modification to a slower rate is beneficial in a programme aiming to alleviate symptoms of cluttered speech.
Table 6 Objective Measures of the Rate of Speaking (words per minute) for Spontaneous Speech and Reading from the Pre- to the Post-Therapeutic Recording

\begin{tabular}{|l|c|c|}
\cline { 2 - 3 } \multicolumn{1}{c|}{} & \multicolumn{2}{c|}{ TOTAL AMOUNT OF WORDS } \\
\cline { 2 - 3 } \multicolumn{1}{c|}{} & PRE-INTERVENTION & POST-INTERVENTION \\
\hline CONVERSATION & 179 & 108 \\
\hline READING & 153 & 119 \\
\hline
\end{tabular}

\section{ATTITUDE}

Table 7 shows that there has been a meaningful change in attitude from pre- to post-intervention, as assessed by a reduction in the score. Pre-intervention scores, which showed that the subject was aware of his problem, contradicts reports that the clutterer is relatively unaware of the problem and should thus score low on Erickson's (1969) S-Scale (Hahlow in Dalton 1983). Sóme authorities have observed however, that clutterers often acknowledge that they are not satisfied with their speaking and reading abilities (Weiss 1964). The post-intervention score, which shows a marked change in the subject's attitude, súpports the hypothesis of Andrews and Cutler (1974), that attitude change occurred after the achievement of fluent speech in the clinic, and when the subject had completed a series of speaking assignments outside the clinic. The acquisition of a better selfconcept and a more positive attitude towards speech is in keeping

Table 7 Analysis of Changes in Therapeutic Assessment of Attitude from the Pre- to the Post-Therapeutic Recording

\begin{tabular}{|l|c|l|}
\hline \multicolumn{1}{|c|}{ TEST } & SCORE & \multicolumn{1}{c|}{ INTERPRETATION } \\
\hline $\begin{array}{l}\text { S-Scale of Communica- } \\
\text { tion Attitudes } \\
\text { (Erickson 1969). } \\
\text { Pre-intervention }\end{array}$ & $31 / 39$ & (i) $\begin{array}{l}\text { Experiences great discomfort } \\
\text { in social conversation situ- } \\
\text { ations. }\end{array}$ \\
\hline $\begin{array}{l}\text { S-Scale of Communica- } \\
\text { tion Attitudes } \\
\text { (Erickson 1969). } \\
\text { Post-intervention }\end{array}$ & $16 / 39$ & $\begin{array}{l}\text { (ii) } \\
\text { (iii) Novere speech problems. }\end{array}$ \\
& & (i) $\begin{array}{l}\text { Experiences little discomfort } \\
\text { in social conversation situ- } \\
\text { ations. }\end{array}$ \\
& (ii) $\begin{array}{l}\text { Mild speech problems. } \\
\text { (iii) Improvement in speech. }\end{array}$ \\
\hline
\end{tabular}


with the therapeutic goals of Shames and Florance (1980). It must be kept in mind however that attitude change could be due to the fact that he received therapy, and not necessarily as a result of this particular programme. Furthermore, the findings of testing immediately after completion of therapy could have influenced these results in that the change in attitude may reflect the subject's desire to please his therapist by showing improvement. These hazards are often inherent in subjective attitude testing.

\section{CONCLUSIONS}

A therapy programme which differs from previous approaches towards cluttering was used with one clutterer and was found to be clinically effective. While there are obvious limitations in using only one subject, a single case study design does enable the experimenter to make a preliminary investigation into the possible efficacy of certain procedures. A study such as this can be considered as a first step in the investigation of the application of a specific therapy procedure to a population for whom, up to now, few treatment procedures have been evolved.

Although the subject did not make meaningful changes with regard to prosodic elements, there was a meaningful post-therapeutic improvement in all the other parameters tested. The fact that at the end of the period of intensive therapy, the subject was able to correct himself spontaneously, is evidence that his self-monitoring ability had developed. These findings support the contention of Weiss (1967) and Arnold (in De Fusco and Menken 1979) that a clutterer's speech will improve when attention is called to it.

It is possible that the improvements noted in the patient's speech post-therapeutically arose out of his desire to please the therapist, and as such was an artifact of the patient-therapist relationship. However his ability to modify his speech seems, to some extent, to be a testament to the effectiveness of the therapeutic programme. While it would have been desirable to have had additional postintervention assessments some months after therapy, this was not feasible. Therapy did however continue on a less intensive basis after the conclusion of this study. An informal assessment of the subject's speech, eight months after completion of intensive therapy, showed that he had maintained the improvements noted in his speech and is still motivated to continue working on the programme. According to Weiss $(1964,1967)$, however, clutterers are generally unmotivated to receive therapy.

This study indicated the value of an intensive therapy programme for a clutterer. The motivation and success can be attributed in part to the fact that improvement was established quickly, and thus the effort demanded from the subject was justified by the fluent results achieved. In order to ascertain whether it was this particular fluencybased programme, or the intensive nature of its implementation, research must be carried out utilising this technique on a nonintensive basis.

It may be short-sighted to rely only on clinical performance as an indication of outcome from fluency-based therapy. Measures from clutterers regarding their attitudes toward communication may provide a firm foundation for the amount of treatment required by an individual clutterer in the normalization of attitude or self-concept.

Finally, findings imply that additional emphasis should be given to the maintenance of normal prosody in the treatment of a clutterer. Inflection and stress exercises, to facilitate normal pitch and decrease the monotony of speech, could be used.
In conclusion, if the improvement of these dysfluencies, articulatory errors and a slowing down of the rate of speech enables the clutterer to enhance his intelligibility, as has been shown in this study then the value of this approach, even if presently unquantified, is demonstrated. There is an urgent need for further research, and it seems appropriate to utilize this approach in order to benefit those clients with cluttering symptoms.

\section{REFERENCE LIST}

Andrews, G. and Cutler, J. Stuttering Therapy: The relation between Changes in Symptom Level and Attitudes, J. Speech Hear. Disord. , 39, 312-319, 1974.

Andrews, G. and Ingham, R.J. An Approach to the Evaluation of Stuttering Therapy, J. Speech Hear. Res., 15, 296-302, 1972.

Arnold, G.E. An Attempt to Explain the Causes of Cluttering with the LLMM Theory, Folia Phoniatrica, 22, 247-260, 1970.

Becker, K.P. and Grundmann, K. Investigations on Incidence and Symptomatology of Cluttering, Folia Phoniatrica, 22, 261-271, 1970.

Bradford, D. Cluttering, Folia Phoniatrica, 22, 249-272, 1970.

Dalton, P. Maintenance of Change: Towards the Integration of Behavioural and Psychological Problems. In Approaches to the Treatment of Stuttering, Dalton, P.(Ed.) Croomhelm, Kent, 1983.

Dalton, P. and Hardcastle, W.J. Disorders of Fluency and their Effects on Communication, Edward Arnold, Guildford, 1977.

De Fusco, E.M. and Menken, M. Symptomatic Cluttering in Adults, Brain Lang. , 8, 25-33, 1979.

Erickson, R.L. Assessing Communication Attitudes Among Stutterers, J. Speech Hear. Res., 12, 711-724, 1969.

Grewell, F. Cluttering and its Problems, Folia Phoniatrica, 22, 301-310, 1970.

Ingham, R.J. and Andrews, G. Stuttering: The Quality of Fluency After Treatment, J. Commun. Disord., 4, 279-288, 1971.

Johnson, W., Darley, E. and Spriestersbach, D.C. Diagnostic Methods in Speech Pathology, Harper and Row Publishers, Inc., New York, 1963.

Langová, J. and Morávek, M. Some Results of Experimental Examinations among Stutterers and Clutterers, Folia Phoniatrica, 16, 290-296, 1970.

Le Mesurier, H.G. and McIntosh, E. The Pocket Oxford Dictionary, Fourth Edition, Oxford University press, Clarendon, London, 1966.

Luchsinger, R. and Arnold, G.E. Vice - Speech - Language, Chapter 6, Belmont, California, Wadsworth, 1965.

Ryan, B.P. and Van Kirk, B. The Establishment, Transfer and Maintenance of Fluent Speech in 50 Stutterers using Delayed Auditory Feedback and Operant Procedures, J. Speech Hear. Disord. 39, 3-10, 1973.

Shames, G.H. and Florance, C.L. Stutter-Free Speech, A Goal for Therapy, Charles, E., Merrill Publishing Company, Toronto, 1980.

Silverman, F.H. Research Design in Speech pathology and Audiology, Prentice-Hall, Englewood Cliffs, New Jersey, 1977.

Uys, I.C. Psigoneurologiese Disfunksie: 'n Tipering Volgens Sekere Spraakpatologiese Verskynsels, Doctoral Dissertation in Speech Pathology, University of Pretoria, Pretoria, 1974.

Weiss, D. A. Therapy for Cluttering, Folia Phoniatrica, 12, 216-223, 1960.

Weiss, D.A. Cluttering, Prentice-Hall Foundations of Speech Pathology Series, 1964.

Weiss, D.A. Cluttering, Folia Phoniatrica, 19, 233-263, 1967.

Wolk, L. Diagnostic Evaluations of an Adult Clutterer: A Case Report. Unpublished M.A.(Spéech Pathology) Dissertation. Department of Speech Pathology and Audiology, University of the Witwatersrand, Johannesburg, 1980. 